\title{
Medical SPIN: misinformation by another name
}

\author{
Abe Fingerhut $\cdot$ François Lacaine $\cdot$ Alfred Cuschieri
}

Received: 16 January 2015/Accepted: 24 January 2015/Published online: 21 February 2015

(C) Springer Science+Business Media New York 2015

Good care of patients entails making several decisions. These include (1) which investigations are necessary to establish the correct diagnosis; (2) what is the best therapeutic management scheme for the patient, often with consideration of alternative options with different objectives; (3) how best to carry out the management involving not just the planned treatment but also with the ability to cope with any unexpected findings, and/or complications; and lastly, (4) how to ensure completion of care after the intervention; every step with the goal to ensure the best clinical outcome for the patient, while guaranteeing patient safety.

Each single step is dependent on how strongly the attending clinician can rely on the outlined management plan, and this in turn translates into how strongly the care provider can base decisions on the level of evidence available in the published scientific literature [1-6].

\section{What is SPIN?}

"Spin" according to available evidence has its origins in the way politicians (or their advisors, often referred to as spin doctors) are able to "turn" (or "spin") opinions around to suit their needs, arguments or goals. Widely used in public relations, SPIN is a particular form of hype, providing a camouflaged interpretation of events to sway public opinion for or against an idea, a person or organization. All too often, in many domains, SPIN is synonymous with deceitful, misleading and disingenuous tactics fostering misinformation.

A. Fingerhut $\cdot$ F. Lacaine $\cdot$ A. Cuschieri $(\square)$

Dundee, Scotland, UK

e-mail: a.cuschieri@dundee.ac.uk
In medicine, Boutron et al. [1] have defined SPIN as a "focus on statistically significant results (within group comparison), secondary outcomes, subgroup analyses, modified population of analyses" to a disproportionate extent, such that "nonsignificant results are ignored or minimized." Medical SPIN is often committed in reporting clinical studies comparing two treatment modalities, when one treatment is portrayed as being superior, merely by selective emphasis on certain data (e.g., subgroup analysis) indicative of significant difference between the two regimens, while overlooking other nonsignificant differences between the two treatments. The same authors conclude SPIN as "interpreting statistically nonsignificant results for the primary outcomes as demonstrating treatment equivalence or comparable effectiveness," in essence stating that treatment under scrutiny was equal to or as efficacious as the control, or emphasizing the beneficial effect of the treatment despite statistically nonsignificant results. This is ignoring the beta or type II error that of concluding that there is no difference when in fact there is.

While scientists sometimes behave like politicians, unlike the latter who usually get away with it, because political SPIN is ephemeral, care takers are ethically bound to truth. The transient nature of political SPIN was emphasized in the UK House of Commons (Parliament) by the late Harold Wilson (1916-1995) UK Labor Prime minister, in his memorable statement to the House "A week is a long time in politics [7]." In sharp contrast, medical SPIN is not easily forgotten or overlooked, nor should it be because of its clear potential for patient harm.

This editorial is far removed from political or indeed any other form of SPIN. Instead, it specifically addresses the way a handful of medical writers "spin" their conclusions round in such a way that the astute reader gets the impression that the author has massaged the data favoring 
preconceived notions [2]. Presumably, this is done in the belief that an inference that something is possibly better will have a greater impact on the readers that a conclusion that the two are equal.

\section{How to avoid it?}

This is a plea to both senior and academicians and young researchers that a minimum of knowledge in clinical research methodology is essential for medical writing. Specifically, clinicians must have a sound working knowledge of the tools necessary to address the following: efficacy of diagnostic tests (sensitivity, specificity, positive and negative predictive values, receiver operating characteristic curves, and kappa index), validity of the methodology and prognostications used, risk analysis (hazard ratio and multivariable analysis) as well as indications (how to do it, when to do it, and which patient needs it) and patient outcomes (cure, palliation, without unnecessary risks and minimal complications) in sufficiently and adequately powered studies, enabling acceptance of any observed difference (or its absence) with the result being due to pure chance less than $5 \%$, (the famous " $p$ " value). Finally yet importantly, it is necessary for the writer and reader, to distinguish clearly between statistical significance and clinical significance and when causality is established (as opposed to association).

When no valid comparisons are made, no recommendation should be suggested, and no superiority inferred or claimed. Equally, when only univariate analysis is reported, there can be only associations, no causative implications. When a study is underpowered (and there so many such randomized clinical trials), which may conclude that there is, or is no difference...the reality is that one cannot draw any valid conclusion from these studies.

How to rid the medical literature of SPIN depends on us all. To publish correctly, the medical writer has to appreciate and understand these principles and write accordingly. Courses in medical writing and methodology exist, but they do not yet have their proper place in the medical community and training programs. Courses in medical writing and clinical methodology have to be more frequently offered, and the medical community needs to recognize their importance. The peer reviewer has to, by virtue of his seminal role, scrutinize the manuscript under review, to ensure that no error goes unrecognized and to point such errors in a positive fashion to the author(s). Lastly, editors of peer-reviewed medical journals have to ascertain assiduously before acceptance for publication, that the manuscript reports the findings in strict accordance with these rules without any SPIN.

A call to arms! Editors, reviewers, writers and readers alike: take evidence-based medicine seriously. The quality and correctness of care, the ethical engagement we have with our patients, are at stake.

\section{References}

1. Boutron I, Dutton S, Ravaud P, Altman DG (2010) Reporting and interpretation of randomized controlled trials with statistically nonsignificant results for primary outcomes. JAMA 303:2058-2064

2. Clavien PA, Puhan MA (2014) Biased reporting in surgery. BJS 101:591-592

3. Dickersin K, Chalmers I (2011) Recognizing, investigating and dealing with incomplete and biased reporting of clinical research: from Francis Bacon to the WHO. J R Soc Med 104:532-538

4. Dwan K, Altman DG, Arnaiz JA, Bloom J, Chan A-W et al (2008) Systematic review of the empirical evidence of study publication bias and outcome reporting bias. PLoS ONE 3(8):e3081. doi:10. 1371/journal.pone.0003081

5. Hopewell S, Loudon K, Clarke MJ, Oxman AD, Dickersin K (2009) Publication bias in clinical trials due to statistical significance or direction of trial results. Cochrane Database Syst Rev Issue 1. Art. No.: MR000006. doi:10.1002/14651858.MR00 0006.pub3

6. Song F, Parekh S, Hooper L, Loke YK, Ryder J, Sutton AJ et al (2010) Dissemination and publication of research findings: an updated review of related biases. Health Technol Assess 14(8)

7. BBC-National 4 Modern Studies - Political spinwww.bbc.co.uk >... > United Kingdom Also includes an interview with Guto Harri, former $\mathrm{BBC}$ political correspondent and nowspin doctor for the Mayor of London, Boris Johnson. They both speak 